\title{
Innovative and Practical Personnel Training System of Electronics Science and Technology Professionals
}

\author{
Di zhigang, Jia chunrong \\ College of Electrical Engineering \\ Hebei United University \\ Hebei Tangshan, China, 063009 \\ e-mail: dzg0512@126.com
}

\begin{abstract}
Photoelectron technique has become core content of electronics science and technology professionals, and has become the pillar and basic of photoelectron information industry. In order to strengthen cultivation of students' professional ability, and highlight the characteristic of photoelectron, this paper presents an innovative and practical personnel training system on electronics science and technology professionals. The system utilized tamping professional base, broadening professional knowledge, strengthening practice technical ability and highlight the application of photoelectron as cultivation principal line. Also, used the application of photoelectron as professional characteristic to promote education work. This plan built rational and complete personnel training system, both received teaching benefits teachers as well as students, and improved the practice and innovation ability of students.
\end{abstract}

Keywords-electronics science and technology; opto-electric; personnel training;innovation;

\section{INTRODUCTION}

In 21st century, with the development of modern science and technology, human is entering a brand new timesInformation times, whose distinct characteristics of the times is basic industry such as energy, traffic, and information will be developed highly, and can fully satisfy people's livelihood and social development. While the basic of it is photoelectron technique and microelectronic technique, which belong to Electronics Science and Technology Professionals. The typical technique can be shown in figure 1 and 2 .

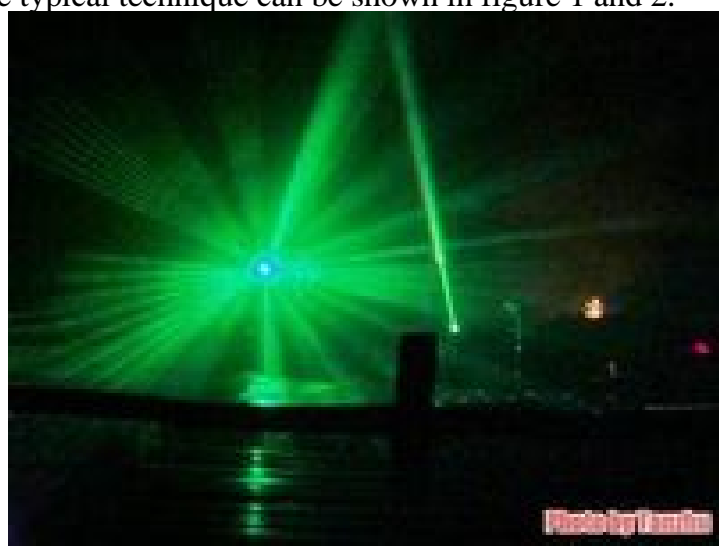

Figure 1. The typical technique of photoelectron technique.

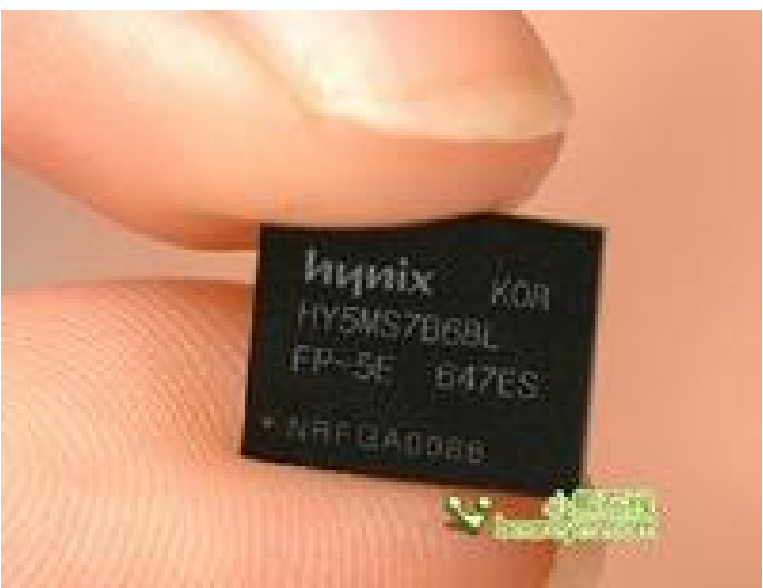

Figure 2. The typical technique of microelectron technique.

Photoelectron technique is a burgeoning technique which combines optics and electronic technique. With the transition from industrial society to informational society, photoelectron technique has developed quickly and permeated in every parts of national economy, and has become the pillar and base in photoelectron information industry, one of important pillar in information society[1]. Photoelectron technique involves frontier knowledge of photo-electronics, optics, electronics and computers, it is a high and new multidisciplinary technology which permeates and intersect mutually. Photoelectron technique mainly includes fiber sensor, photo-electricity detection, fiber communication, photo-electricity display and optical storage.

In recent years, many countries, especially developed countries, are developing photoelectron technique vigorously, and America and Japan have representativeness[2]. Our country began developing photoelectron in Six Five Plan, and the National 863 plans projects supported on photoelectron device and its integration technique in 1986. Besides, the National Natural Science Fund Committee supported the research work on photo-electronics and relative courses. Since then, because of the great support of National 863 Plans and National Natural Science Fund Committee, a batch high-level science foregoers and key persons of ability have been cultivated. The National 863 plan projects are the force to start and develop photoelectron technique, and impel to receive great progress[3]. 
As mentioned above, in order to suit for the development of society and improve the students' innovation and practice ability, an innovative and practical personnel training system on electronics science and technology professional was proposed, so as to receive teaching benefits teachers as well as students, and improve the practice and innovation ability of students.

\section{FUNCTIONS AND SIGNIFICANCE OF OPTIMIZATION IN TRAINING SYSTEM}

The project utilized tamping professional base, broadening professional knowledge, strengthening practice technical ability and highlight the application of photoelectron as cultivation principal line. Also, used the application of photoelectron as professional characteristic to promote education work.

\section{A. The segment of theory education}

According to the characteristics of students and the realization of cultivation object, the segment of theory education includes three modules, namely general studies, platform of professional foundation and platform of professional education, which links with one another. As a result, professional cultivation line and object was expressed obviously, and made education system more complete, more vivid.

\section{B. The segment of practice education}

In order to realize the professional cultivation object, the segment of practice education was strengthened on the basis of theory education, so as to cultivate the students' manipulative ability and innovation ability. This segment includes replication ability, design ability and comprehensiveness ability practice contents. On the basis of above, the students were encouraged to participate in advisor's research and science and technology innovation mega games actively. By this mode, the students' practice ability is cultivated, also teachers' practice education is promoted further.

\section{CONSTRUCTION OF PERSONNEL TRAINING SYSTEM}

\section{A. The research contents}

According to the current status of electronics science and technology professionals in our school, construction train of thought which strengthens the characteristic of photoelectron and optimizes professional course system reform and cultivation principal line which tamps professional base, broadens professional knowledge, strengthens practice technical ability and highlights the application of photoelectron was presented, so as to optimize professional construction plan and training system.

Enhancing the construction of teachers troops and courses system, and on the basis of this, carrying on reform the teaching method and means, so as to improve the science level of teachers, strengthen the theory base of students, consummate their knowledge structure. By means of these approaches, the practice and innovation ability of students could be improved, and the purpose which teaching and research are inseparably interconnected, and teaching benefits teachers as well as students could be realized.

\section{B. The research objects}

According to the current status and developing foreground of photoelectron technique in our country, combining with the physical truth of electronics science and technology professional in our school, the professional cultivation plan was carried on optimizing, and take on cultivation research application talents as ultimate object, so as to suit for the requirements of modernization construction and information industry developing. Besides, this plan can realize objects as follows: (a). make students possess strong natural science basis and broad professional knowledge. (b). have innovation and practice ability and following the tracks of grasping new theory, new knowledge and new technique. (c). can devote themselves to systematic research and development, design, maintenance and management in sensing field, inspection field and semiconductor engineer field.

\section{The implement plan of personnel cultivation system}

Teaching model in personnel cultivation system. In traditional teaching model, students mainly receive teaching material knowledge, so that they are short of discovering and practice process, then they can not contact frontier scientific knowledge with what they have learned. Besides, teaching places were confined in classroom or laboratory, so made them come apart from social reality, then they felt that what they have learnt is no use. The students cultivated in traditional teaching model have not been exploited their tremendous potential, so led to their poor innovation ability[4]. In order to change this plight, the teaching model which take on cultivating practical and innovative talented persons as object was proposed. In this novel teaching model, the emphasis is not book learning, but tamping professional base, broadening professional knowledge, strengthening segment of practice education and improving innovation ability, thus make the students utilize their theory knowledge in practice flexibly, and strength their ability of discovering problems and solving them. This teaching model can exploit students' potential to the maximum, and provide excellent conditions for them, as a result, achieved the object which cultivates their ability of scientific research and practice innovation.

Highlight the characteristic of photoelectron technique, ensuring personnel training system. The construction of course is the most important in colleges and universities, also it is effective shortcut to improve practice and innovation ability, and powerful guarantee to improve teaching quality. In order to achieve ultimate object of personnel training, especially to cultivate practice and innovation ability, the cultivation plan of tamping professional base, broadening professional knowledge, strengthening practice technical ability and highlight the application of photoelectron was proposed. On the base of this, construct a high level professional teachers troops by brain gain and personnel 
training, and then establish high level technological innovation platform to achieve course characteristic.

Strengthen the cultivation of practice technical ability. The cultivation of practice ability, research ability and innovation ability is the important part in higher education. As for undergraduates, practice ability is more important. Except for steady basic knowledge and broad professional knowledge, engineering undergraduates must possess the practice ability of parsing and solving problems, so as to adopt to all kinds of operating posts. In order to achieve this goal, the project increased the ratio of practice segment, highlight the cultivation of practice ability. First, we set up Electrical and electronic engineering practice, Photoelectric practice, Curriculum design of fiber sensor system, Comprehensive curriculum design and Specialized production practice. Second, we set up excellent engineer project, cooperate between colleges and enterprises to cultivate the practice ability, ask some students to complete graduate project in enterprise, so as to improve their practice ability further.

Highlight the application of photoelectron technique, emphasize the cultivation of innovation ability. Innovation ability must be based on acquirement proficiency in theory knowledge[5]. After learning the courses of Principle and technique of Laser and Photoelectron technique, the students will learn stem courses such as Fiber technique, Fiber sensor and application, Photoelectron detection technique and application, photoelectron display technique. Thus, the students' ability of engineering practice and innovation was cultivated, and they can devote themselves to systematic research and development, design, maintenance and management and so on.

In order to promote individual development, the project puts more effort on cultivating the innovation mentality and ability. First, invite famous experts to present frontier report and ask students to join in teacher's research, thus, the students can both grasp professional scientific research dynamic and strengthen their innovation ability. Second, on the base of professional English and bilingual education, encourage the students to read proficiency English literatures, so as to stimulate their innovation mentality, then enhance their innovation ability substantially.

\section{PROFESSIONAL FEATURES}

Electronics Science and Technique Professionals of our school orients it's work to the development of modern information technology, stress is put on photoelectronic technique, and microelectronic technique as supplement. The concrete features are as follows:

a). Configuration of curriculum system. Take fiber sensor curriculum system and photoelectric inspection curriculum system as kernel.

b). Cultivation on students. Try to cultivate the research and practical ability on fiber sensor, photoelectric inspection, image processing and semiconductor manufacture, and cultivate them to analyze, design, optimize and maintain system.

c). Practice education. In future, we will strength on practice training on photoelectronic technique and electronic technique, so as to cultivate practice and application professionals.

\section{CONCLUSIONS}

The paper presented a novel personnel training system. First, this project was approved by expert committee of our school, and was set up as key point education reform project, and supported the highest fund in our school. Second, the project has the important promotional value, it can optimize course system, improve teaching quality, optimize the knowledge structure of students, strengthen professional knowledge, cultivate their engineering practice ability and innovation ability, make them devote themselves to systematic research and development, design, maintenance and management in sensing field, inspection field and semiconductor engineer field.

The project was approved by 2008 year of graduations in our major. we can conclude from their graduation project that they have changed so much. First, they have integrated their knowledge. Second, they have achieved transformation from knowledge-based to capacity type, from the imitation type to innovation type, from unitary type to composite type stage by stage. Compared with previous graduations, the whole quality has been improved obviously. Although we have received some effect, we have to go on exploring and practicing on personnel training system, because as we know-Learning is an endless process, so does teaching. And we will try to cultivate more and more innovation practice type students.

Before you begin to format your paper, first write and save the content as a separate text file. Keep your text and graphic files separate until after the text has been formatted and styled. Do not use hard tabs, and limit use of hard returns to only one return at the end of a paragraph. Do not add any kind of pagination anywhere in the paper. Do not number text heads-the template will do that for you.

\section{ACKNOWLEDGMENT}

The work was supported by instruction reform key research funds of Hebei United University.

\section{REFERENCES}

[1] China Economic Net. "The current status and development direction of photoelectron information industry”, 2007. http://www.cnopt.com/ article/200703/03095262007.html.

[2] Shanghai science and Technology Information Institute, “Totality development situation of world photoelectron industry in 2009”, http: //www.istis.sh.cn/ list/ list.aspx? id=6643. 2009

[3] Xie S. Z., "Review of 15 years' achievements and forecast of Tenth five on 863 Plan photoelectron subject”. http://www. doc88.com/ p977394545590.html, 2012.

[4] Guan Rongfeng, Dong Xingfa, Xiao Jinqiu, Course Group Construction and Reform of Optoelectronics \& Optical Communications of Electronic Information Science and Technology Specialty”, J. Higher Education of Sciences, vol. 93, pp. 110-113, 2010.

[5] Peng Runwu, Tang Lijun, Guo Yu, "Cultivate photoelectron professional invovation talentd people combined with frontier science”, J. China Electric Power Education, vol. 150, pp. 41-42, 2009. 